\title{
Fifteen years of experience in predictive testing for Huntington disease at a single testing center in Victoria, Australia
}

\author{
M. Kaye Trembath, $P h D^{1}$, Roslyn J. Tassicker, MSW', Veronica R. Collins, PhD ${ }^{1}$, Sue Mansie, BSW', \\ Leslie J. Sheffield, FRACP, MSc', and Martin B. Delatycki, FRACP, $P h D^{1}$
}

\begin{abstract}
Purpose: This retrospective study describes 15 years of experience in predictive testing for Huntington disease at a single center in Victoria, Australia. Method: Data collected on 756 participants included age, gender, family history, prior risk and the age at which this risk became known, exposure to Huntington disease, number of children, and proximity to the testing center. Results: Some $57.8 \%$ of participants were female, and $88.8 \%$ had a $50 \%$ risk of developing Huntington disease. The mean age at entry was 40.4 years and was gender-independent. Of all completed tests ( $n=648$ ), 37.5\% gave high-risk results, and $3.2 \%$ were in the zone of reduced penetrance. The 14.3\% who withdrew from testing tended to be younger and childless, lacked exposure to severe Huntington disease, and more often at $25 \%$ or less risk. Some $32.4 \%$ of candidates presented for testing within 1 year of becoming aware of their risk, and most of these individuals had little or no exposure to severe Huntington disease. Those whose exposure was considerable waited on average for more than 13 years. Among the most inexperienced candidates were a group of "adoptees" (raised away from their biological family). Maternal transmission was the source of risk for 19 of 20 adoptees. Conclusion: This study illustrates the significance of exposure to Huntington disease and its impact on the timing of testing. Genet Med 2006:8(11):673-680.
\end{abstract}

Huntington disease (HD) is an autosomal dominant neurodegenerative disorder in which the main sites of pathology are the basal ganglia and cerebral cortex. It is characterized by cognitive and motor impairment (typically chorea), and is often accompanied by psychiatric and/or personality affliction. Symptoms most often develop in adult life, leading to dementia and death on average 15 to 20 years after onset. ${ }^{1,2}$

Testing of the genetic status of asymptomatic at-risk individuals became possible following the discovery in 1983 of a tightly linked marker (G8) that localized the HD gene to chromosome $4 .{ }^{3}$ The first predictive test results worldwide were given in $1987^{4}$ and in the state of Victoria (Australia) in 1989.5,6 Because of the necessity of obtaining blood samples from multiple family members, the uninformative nature of some family pedigrees, and the possibility of recombination between the markers and the gene, linkage analyses were not suitable for all those at risk requesting testing. ${ }^{4}$ In 1993 the mutation associated with HD was characterized as an unstable CAG repeat within exon 1 of the IT15 gene. ${ }^{7}$ Measurement of the number

From the ${ }^{1}$ Bruce Lefroy Centre for Genetic Health Research, Murdoch Childrens Research Institute, and ${ }^{2}$ Genetic Health Services Victoria, Royal Children's Hospital, Victoria, Australia.

Martin Delatycki, FRACP, PhD, Bruce Lefroy Centre for Genetic Health Research Murdoch Children's Research Institute, Flemington Rd, Parkville Victoria 3052, Australia.

Submitted for publication February 16, 2006.

Accepted for publication August 16, 2006.

The authors have no conflicts of interest in relation to the data presented in this article.

DOI: 10.1097/01.gim.0000245633.97952.f1 of CAG repeats by direct mutation analysis obviated the need for obtaining DNA samples from other family members, thus enhancing the autonomy and privacy of individuals seeking to know their genetic status and providing them with a definitive predictive test.

This study was designed to analyze the first 15 years of HD predictive testing in Victoria to the end of 2004 and to compare our experience with other studies. Counseling, neurologic assessment, and genetic analyses were coordinated through the Genetic Health Services Victoria (known before 2001 as the Victorian Clinical Genetics Service), leading to a standardized approach and consistency and completeness in recording not possible in many studies.

\section{MATERIALS AND METHODS}

\section{Predictive testing program}

Victoria's only testing center services a population of approximately 5 million. The program is free of charge and centered in metropolitan Melbourne, a large city located centrally but in the southern part of the state. Components of the program include a number of counseling and genetic consultations, a neurologic/neuropsychiatric assessment, and a DNA test. ${ }^{8}$ For the purposes of this study, entry into the program was defined as face-to-face consultation with a counselor and/or neurologist associated with the program. Thus, phone contact seeking preliminary information did not constitute entry. The number of predisclosure consultations was generally approxi- 
mately three or four, although the range was wide, and follow-up contacts were as needed and thus variable in number. Two consultations in a single day at the metropolitan center, phone counseling, and attendance at nonmetropolitan outreach clinics were measures adopted to meet the needs of rural candidates. Asymptomatic status was not always clinically confirmed because some candidates declined the neurologic examination that was offered to all; however, predictive testing proceeded if the candidates believed themselves to be asymptomatic. Completion of testing was defined as the candidate having received the result of the DNA test. When the candidate chose not to receive the result, the test was defined as incomplete and the candidate was deemed to have withdrawn. The stage reached before withdrawal was recorded. Those cases considered to be ongoing at the end of 2004 for whom a result was likely to be given in the near future were excluded from this study, because they were neither complete nor had the candidates withdrawn from testing. The minimum age for predictive testing in Victoria is usually 18 years.

When candidates presented with a risk of $25 \%$, every effort was made to offer their at-risk parent testing first (if still living). Most of the group at less than $25 \%$ risk were only distantly related to an affected person, presenting different counseling issues to those directly descended from an affected person.

\section{Data collected}

Ethics approval for this study was obtained from the Ethics in Human Research Committee of the Royal Children's Hospital, Melbourne.

Data on 756 entrants into the program were drawn from genetic files, counseling files, and laboratory records held at Genetic Health Services Victoria and compiled into an anonymous database. The data included gender, age, prior risk and the length of time the risk had been known, level of prior exposure to $\mathrm{HD}$, family history (including gender, CAG repeat number and the age of onset of HD in affected relatives, and whether or not the candidate was raised by their biological family), outcome of any neurologic testing, and geographic proximity to the testing center. The level of prior exposure to HD was categorized according to whether the candidate had none, had been exposed only to the early symptoms of the disease, or had observed the advanced stages and/or death of a family member. On the basis of postcode data, participants were assigned to one of four geographic localities in relation to the testing center: less than $20 \mathrm{~km}, 20$ to $100 \mathrm{~km}, 100$ to $300 \mathrm{~km}$, or more than $300 \mathrm{~km}$.

Before 1993, linkage analysis of markers linked to the HD mutation within a candidate's family was used to provide a modified risk. The final risk was calculated, allowing for the probability of recombination events, using the MLINK component of the LINKAGE computer program (obtained from Lathrop et al. ${ }^{9}$ ). A CAG repeat number derived from direct mutation testing of 40 or more indicates the presence of an HD allele with full penetrance and defines a gene-positive result. A zone of reduced penetrance, where some individuals remain asymptomatic, corresponds to alleles with 36 to 39 CAG re- peats. Alleles with 35 or less repeats define a normal or genenegative result. ${ }^{10}$

\section{Data analysis}

Data were entered into a Microsoft Access database (Microsoft Corp., Redmond, WA). Descriptive analysis was undertaken using Microsoft Excel and the Statistical Package for the Social Sciences (version 12.0, SPSS Inc, Chicago, IL). Data are presented as means and standard deviations (SDs) for continuous variables and proportions for categoric variables. The statistical significance of differences in mean levels of continuous variables was assessed using $t$ tests for independent samples for comparisons between two groups and one-way analysis of variance for comparisons across three groups. Differences in proportions between groups were assessed for statistical significance using the chi-square test for association. To test whether observed proportions in a single group followed the expected distribution, for example, a 50:50 gender distribution, the chi-square goodness-of-fit test was used. The criterion for statistical significance was $P$ less than .05 .

\section{RESULTS}

The predictive testing program in Victoria began in 1987. The annual entry since then is detailed in Figure 1A, reaching a peak of 87 entrants in 1994 shortly after the introduction of direct DNA mutation analysis. In total, 756 people commenced testing; 95 started when testing was done by linkage analysis and the remainder since that time. In 648 cases, the testing and counseling process was completed and a result was given. Figure 1B shows the annual distribution of these completed tests.

\section{DEMOGRAPHIC DATA FOR PROGRAM ENTRANTS}

\section{Age and gender}

Demographic data for the study cohort are presented in Table 1. There were 437 females (57.8\%) and 319 males (42.2\%) who entered the program, with a mean age at testing of 40.4 years $(\mathrm{SD}=14.4)$. Analysis of age by gender shows means of 40.5 years for females and 40.2 years for males, and a similar age distribution (Fig. 2). One candidate, who underwent testing of her own volition, received a result at $171 / 2$ years because of family planning intentions. The remainder of the results were given to individuals aged 18 years or more.

\section{Children}

Before testing, $67.3 \%$ of candidates had one or more children (Table 1), and four were pregnant at the time of entry. The relative proportion of the group seeking testing before having children has not changed significantly since the inception of testing; in the period before the introduction of the direct mutation test, $38.8 \%$ of candidates were childless compared with $35.3 \%$ since that time $(P=.53)$. 

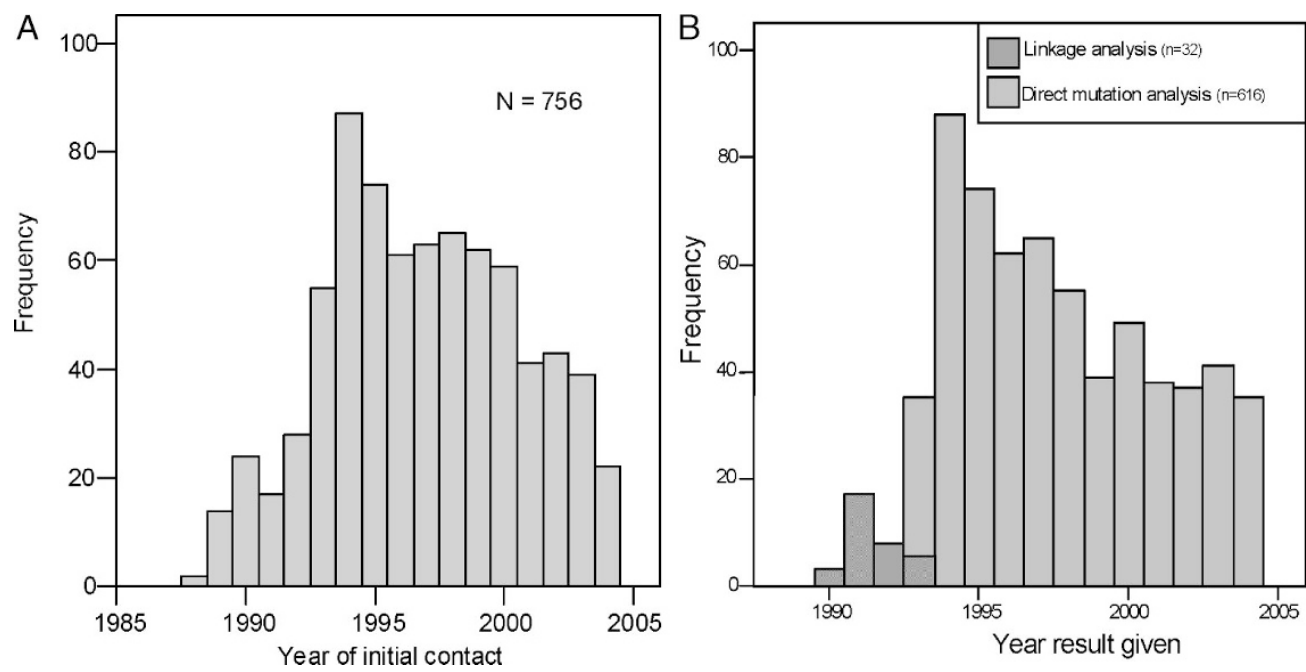

Fig. 1. A. The number of candidates entering into the predictive testing program for HD per year. B. The number of tests completed in any given year and the method of analysis used.

\section{Family history}

In $83.3 \%$ of cases an affected parent (or one with an expanded HD allele) was directly identified. In an additional $8.1 \%$, the at-risk parent could be implied from diagnoses in maternal or paternal relatives. A maternal family history of $\mathrm{HD}$ was significantly more common than a paternal one $(54.8 \%$ vs. $36.5 \%, P<.001)$. There were 65 cases $(8.6 \%)$ with no clearly documented family history of HD before the current generation. Most of these candidates became aware of their risk after the diagnosis of HD in a sibling (53 cases) or a child (6 cases).

\section{Prior risk}

In total, $88.8 \%$ cases had a prior genetic risk of $50 \%$. One person presented with a $75 \%$ prior risk because both parents were affected, and $8.1 \%$ presented with a risk of $25 \%$ and required particularly careful exploration and multistaged counseling. In eight cases, the parent with a prior risk of 50\% subsequently chose to be tested first, and the candidate's prior risk of $25 \%$ was modified during the testing process. Three candidates, whose risk was nullified by their parent receiving a genenegative result, withdrew. Two of the five whose parents tested gene positive, and whose risk was modified to $50 \%$, also withdrew.

\section{Proximity to the test center}

Australian Bureau of Statistics figures for June 2004 indicated that $24 \%$ of Victoria's 4.98 million residents live more than $100 \mathrm{~km}$ from the center of Melbourne, ${ }^{11}$ as do $25.3 \%$ of program participants. Although we do not know the precise distribution of the at-risk population it would seem that distance from the testing facilities does not impact the rate of presentation for testing $(P=.42)$. However, living more than $100 \mathrm{~km}$ from the testing center affects the rate of completion, with $35.1 \%$ of those who withdrew and $23.8 \%$ of those who completed testing living in this region $(P=.024)$.

\section{Prior exposure to Huntington disease}

A person's prior exposure to HD was categorized as none ( $14.6 \%$ of cases in whom data were available); having observed only the early symptoms $(34.7 \%)$; or having observed severe illness and/or death of family members with HD (50.7\%). Because of the retrospective nature of this study, such information was not available for 97 of 756 candidates.

\section{Waiting period}

The waiting period was defined as the number of years an individual had known of his or her own at-risk status before presenting for predictive testing. The mean waiting period calculated from 629 valid cases was 9.7 years $(S D=9.3)$ (Table 2). Those at $50 \%$ prior risk waited significantly longer than those at $25 \%$ or less risk before testing (on average 10 vs. 6.5 years, $P=.006)$. The group who waited longest were those who had prior exposure to severe HD (13.4 years). This compares with 4.0 years for those with no exposure and 5.4 years for those having only experience of the early symptoms in their relatives $(P<.001)$.

The age at which candidates first learned of their risk and their level of exposure to HD are also related. Those exposed to severe HD learn at a mean age of 23.8 years compared with 36.2 years for those less experienced $(P<.001)$.

In 204 of 629 of cases (32.4\%), testing occurred within 1 year of the risk becoming known (Fig. 3). The female:male ratio in this group was identical to that of the total cohort $(57.8 \%$ : $42.2 \%$ ). The propensity to test "immediately" (i.e., within 1 year) was considerably higher among those whose experience of HD was very limited $(70.2 \%$ of those with no exposure, $52.6 \%$ of those exposed to early symptoms only, and $11.3 \%$ of those with substantial experience).

\section{Adoption}

A subgroup referred to as "adoptees" was composed of individuals who were raised away from their biological family 
Table 1

Demographic profile of program participants

\begin{tabular}{ccc}
\hline $\begin{array}{c}\text { Total } \\
\text { cohort }\end{array}$ & $\begin{array}{c}\text { Testing } \\
\text { completed }\end{array}$ & $\begin{array}{c}\text { Withdrew from } \\
\text { testing }\end{array}$ \\
$\mathrm{n}=756(\%)$ & $\mathrm{n}=648(\%)$ & $\mathrm{n}=108(\%)$
\end{tabular}

Gender

$\begin{array}{lccc}\text { Female } & 437(57.8) & 373(57.6) & 64(59.3) \\ \text { Male } & 319(42.2) & 275(42.4) & 44(40.7) \\ \text { Age }(y) & & & \\ \text { Mean } \pm \text { SD } & 40.4 \pm 14.4 & 41.0 \pm 14.6 & 36.4 \pm 12.4 \\ \text { (range) } & (16-87) & (16-87) & (17-68)\end{array}$

Children

$\begin{array}{lccc}\text { None } & 241(31.9) & 193(29.8) & 48(44.4) \\ \geq 1 & 509(67.3) & 452(69.8) & 57(52.8) \\ \text { Pregnant at testing } & 4(0.5) & 3(0.5) & 1(0.9)\end{array}$

Family history

$\begin{array}{lccc}\text { Maternal }^{a} & 415(54.8) & 359(55.3) & 56(51.9) \\ \text { Paternal }^{a} & 276(36.5) & 233(35.9) & 43(39.8) \\ \text { Other }^{b} & 65(8.6) & 57(8.8) & 8(7.4)\end{array}$

Proximity to test center

$\begin{array}{lccc}<20 \mathrm{~km} & 282(37.9) & 244(37.7) & 38(39.2) \\ 20-100 \mathrm{~km} & 274(36.8) & 249(38.4) & 25(25.8) \\ 100-300 \mathrm{~km} & 150(20.2) & 125(19.3) & 25(25.8) \\ >300 \mathrm{~km} & 38(5.1) & 29(4.5) & 9(9.3)\end{array}$

Prior risk

$\begin{array}{lccc}50 \% & 671(88.8) & 584(90.1) & 87(80.6) \\ 25 \% & 61(8.1) & 42(6.5) & 19(17.6) \\ \text { Other }^{a, c} & 24(3.2) & 22(3.4) & 2(1.9)\end{array}$

Prior exposure to HD

\begin{tabular}{lccc} 
No prior exposure & $96(14.6)$ & $81(14.5)$ & $15(18.3)$ \\
Early symptoms only & $229(34.7)$ & $193(33.4)$ & $36(43.9)$ \\
Severe disease/death & $334(50.7)$ & $303(52.5)$ & $31(37.8)$ \\
Raised outside family & $24(3.2)$ & $21(3.2)$ & $3(2.8)$ \\
\hline
\end{tabular}

SD, standard deviation; HD, Huntington disease.

${ }^{a}$ One person had HD on both sides of the family and was at $75 \%$ risk.

${ }^{b}$ Indicates no family history before the current generation, for example, risk due to diagnosis in a sibling or offspring.

${ }^{c}$ Twenty-three patients with a risk of less than $25 \%$, generally based on the affected person being a distant relative with a proven or probable diagnosis, in whom the most direct line of risk often had been broken by the death of undiagnosed individuals. In several cases the family history was unclear because of an extended lack of contact.

(adopted or raised in other forms of care). Of this group of 24 individuals (Table 1), 14 were female; the mean age at presentation was $38.5 \pm 12.5$ years, 18 were at $50 \%$ risk, and 9 had no children, although one was pregnant. Where the family history could be traced (in 20/24 cases), the HD risk was maternal in all but one case. Only five "adoptees" recorded substantial prior exposure to HD, and three more had been exposed to early symp-

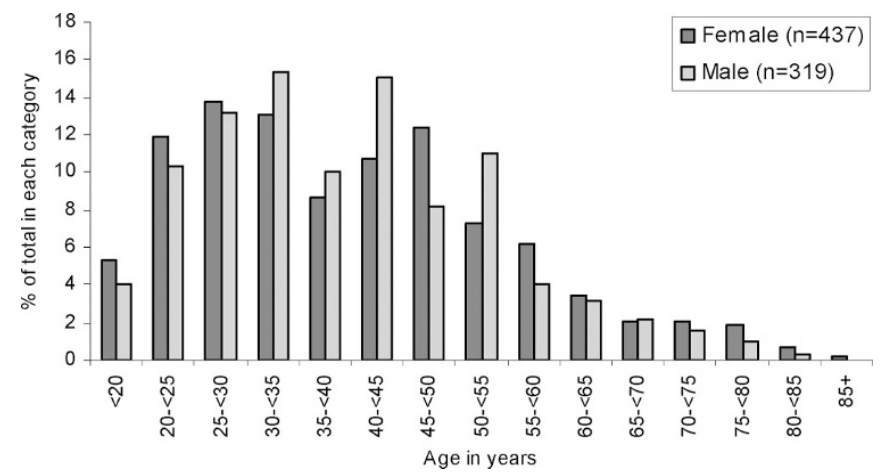

Fig. 2. Age distribution of males and females at the time of their initial contact with the HD predictive testing program.

toms. Although the mean waiting period for the "adoptee" group was 6.1 years (Table 2), 57\% had known their at-risk status for less than 1 year before seeking testing. These data form a subset of the data in Figure 3.

\section{Incomplete tests}

The demographic profile of the 108 people who withdrew from testing is presented in Table 1 . This accounts for $14.3 \%$ of program entrants. Features that most clearly differentiate this group from those who completed testing include the following: younger age (36.4 vs. 41.0 years, $P=.002$ ); childlessness ( $44.4 \%$ vs. $29.8 \%, P=.002$ ); lack of exposure to severe HD (62.2\% vs. $47.5 \%, P=.013)$, being at $25 \%$ or less risk ( $19.5 \%$

\section{Table 2}

Years of knowledge of "at-risk" status before initial contact with the predictive testing program (waiting period)

\begin{tabular}{lccc}
\hline & $\begin{array}{c}\text { Average age when } \\
\text { risk became known }\end{array}$ & $\begin{array}{c}\text { Waiting } \\
\text { period }\end{array}$ & $\begin{array}{c}\text { Valid } \\
\text { cases }^{a}\end{array}$ \\
\hline $\begin{array}{l}\text { Total cohort } \\
\text { Gender }\end{array}$ & $30.0 \pm 15.3 \mathrm{y}$ & $9.7 \pm 9.3 \mathrm{y}$ & 629 \\
$\quad$ Female & $30.1 \pm 16.0 \mathrm{y}$ & $9.9 \pm 9.5 \mathrm{y}$ & 359 \\
$\quad$ Male & $29.8 \pm 14.5 \mathrm{y}$ & $9.3 \pm 9.1 \mathrm{y}$ & 270 \\
Prior risk & & & \\
$50 \%$ & $29.2 \pm 14.7 \mathrm{y}$ & $10.0 \pm 9.3 \mathrm{y}$ & 569 \\
$25 \%$ & $32.4 \pm 15.3 \mathrm{y}$ & $6.5 \pm 8.3 \mathrm{y}$ & 42 \\
Other & $48.3 \pm 21.7 \mathrm{y}$ & $6.4 \pm 9.5 \mathrm{y}$ & 18
\end{tabular}

Prior exposure to HD

$\begin{array}{lrrr}\text { No prior exposure } & 40.2 \pm 19.2 \mathrm{y} & 4.0 \pm 6.2 \mathrm{y} & 84 \\ \text { Early symptoms only } & 34.5 \pm 14.9 \mathrm{y} & 5.4 \pm 6.8 \mathrm{y} & 196 \\ \text { Severe disease/death } & 23.8 \pm 11.4 \mathrm{y} & 13.4 \pm 9.5 \mathrm{y} & 291 \\ \text { Adoptees } & 34.3 \pm 13.9 \mathrm{y} & 6.1 \pm 8.0 \mathrm{y} & 21\end{array}$

Test completion

\begin{tabular}{lrrr} 
Complete & $29.8 \pm 15.3 \mathrm{y}$ & $10.2 \pm 9.5 \mathrm{y}$ & 567 \\
Incomplete & $31.5 \pm 15.3 \mathrm{y}$ & $5.2 \pm 6.5 \mathrm{y}$ & 62 \\
\hline
\end{tabular}

${ }^{a}$ Data were limited to those in whom both years at risk and age at first contact were known. 




Fig. 3. The effect of prior exposure to HD on the timing of testing. Note the uneven scale on the $X$-axis.

vs. $9.7 \%, P=.004)$, and having known of their risk status for a lesser time (5.2 vs. 10.2 years, $P<.001$ ). The gender of the candidate or of the family carrier did not significantly differ from the overall cohort.

\section{Outcome of testing}

The outcome of testing is shown in Table 3. The results have been given to $85.7 \%(648 / 756)$ of those entering the program.

\section{Linkage analysis}

The results based on linkage analysis were given over the period 1989 to 1993. All 35 candidates who underwent testing had been at $50 \%$ prior risk, $57 \%$ were female, and the mean age at first contact was 35.7 years ( $\mathrm{SD}=13.5)$. After testing, $23 \%$ had their risk of inheriting HD modified to high $(88 \%-99 \%)$ and $69 \%$ to low $(2 \%-16 \%)$; the remaining $8 \%$ withdrew because their family analyses were uninformative. Twelve candidates ( 2 who had withdrawn, 4/8 "high-risk" candidates, and 6/24 "low-risk" candidates) subsequently had direct mutation analysis. The 10 cases of previously implied status were all confirmed. The time elapsed until the direct test was taken aver- aged 31 months for the "high-risk" group and 55 months for the "low-risk" group.

\section{Direct DNA test}

Of 648 completed tests (including the linkage tests), the relative frequency of genotypes was $37.5 \%$ gene positive, $3.2 \%$ in the zone of reduced penetrance, and $59.3 \%$ gene negative. The range of CAG repeats in the gene-positive category was 40 to 54 , with a peak at 42 to 43 accounting for $42.4 \%$ of cases (complete data not presented).

The group at $25 \%$ prior risk might be expected to have a lower proportion of gene-positive results compared with the $50 \%$ risk group; however, the observed difference was not significant $(31.0 \%$ vs. $38.9 \%, P=.301)$. A gene-positive result for an individual at $25 \%$ risk inevitably revealed the gene status of his or her at-risk parent, although data were not always available on whether the parent was alive. In the small group whose risk was less than $25 \%$, only $14.2 \%$ (3/21) were gene positive, in line with expectations.

Of the group found to carry a reduced penetrance allele, 13 of $21(62 \%)$ were aged more than 50 years, including seven (33\%) aged more than 70 years. In eight cases testing was prompted by the diagnosis of HD in a sibling or child rather than a parent. This is the only group among those tested in whom the transmitting parent was more often the father (11/17 in whom the family history was clear).

There was considerable disparity between genotype and mean age at presentation: gene positive $=37.1$ years, gene negative $=42.6$ years, and reduced penetrance $=55.4$ years $(P<.001)$. Figure 4 shows the relationship between test outcome and age group (in decades). The ratio of negative/positive results was not heavily skewed in favor of negative results except in the group of those aged 50 years, and the peak for outcomes in the zone of reduced penetrance actually occurred in the group of those aged more than 70 years.

Table 3

Outcome of predictive testing for all completed tests

\begin{tabular}{|c|c|c|c|c|}
\hline Completed tests ${ }^{a}$ & Total & $\begin{array}{c}\text { Gene positive } \\
\text { CAG }>39 \mathrm{n}(\%)\end{array}$ & $\begin{array}{l}\text { Reduced penetrance } \\
\text { CAG } 36-39 \mathrm{n}(\%)\end{array}$ & $\begin{array}{c}\text { Gene negative } \\
\text { CAG }<36 \mathrm{n}(\%)\end{array}$ \\
\hline Total & 648 & $243(37.5)$ & $21(3.2)$ & $384(59.3)$ \\
\hline \multicolumn{5}{|l|}{ Gender } \\
\hline Female & 373 & $130(34.8)$ & $12(3.2)$ & $231(61.9)$ \\
\hline Male & 275 & $113(41.1)$ & $9(3.3)$ & $153(55.6)$ \\
\hline \multicolumn{5}{|l|}{ Prior risk } \\
\hline $50 \%$ & 584 & $227(38.9)$ & $21(3.6)$ & $336(57.5)$ \\
\hline $25 \%$ & 42 & $13(31.0)$ & - & $29(69.0)$ \\
\hline Other $^{b}$ & 22 & $3(13.6)$ & - & $19(86.4)$ \\
\hline Age at initial contact Mean (range) & $41.0 \pm 14.6$ y $(16-87)$ & $37.1 \pm 11.7$ y $(16-80)$ & $55.4 \pm 18.3$ y $(25-87)$ & $42.6 \pm 15.3$ y $(17-84)$ \\
\hline
\end{tabular}

\footnotetext{
${ }^{a}$ Results for 32 tests done by linkage analysis are included as positive ( = high risk) or negative (= low risk), even though in 22 cases a follow-up direct DNA mutation analysis was not performed. The 10 candidates who were tested by both methods have only been counted once.

${ }^{b}$ One had a $75 \%$ risk; all others had less than a $25 \%$ risk.
} 


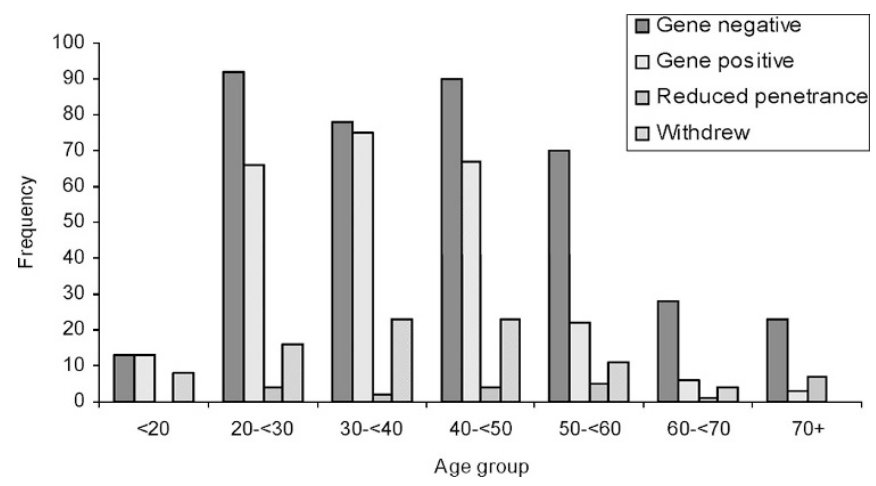

Fig. 4. Distribution by age group and test outcome for 756 individuals presenting for predictive testing for HD.

\section{Data relating to the testing process}

Although all candidates were offered a neurologic examination as part of the predictive testing program, 211 of 756 (28\%) of the total cohort chose not to be assessed. Among those who received a gene test result, $20.4 \%$ declined the offer. There was no gender bias among those choosing not to be examined.

Postdisclosure contacts were provided on a needs basis, averaging 3.4 per candidate. In general, the number varied according to the nature of the result given: the means were 6.0 for a gene-positive result, 2.0 for reduced penetrance, and 1.8 for a gene-negative result. The program of follow-up contacts was not compromised by distance, although a higher proportion of contacts were made by telephone for those living further from the testing center.

\section{DISCUSSION}

In this article we describe the outcomes of 15 years of predictive testing at a single testing center. As with most other large studies, approximately $90 \%$ of candidates came with a prior unmodified risk of $50 \% .{ }^{12-15}$ The finding that $57.8 \%$ of candidates were female is also consistent with international observations, which generally range from $54 \%$ to $63 \% .^{12,14-22}$ Exceptions have only occurred where numbers were small (e.g., $50 \%$ in the study of Kromberg and colleagues ${ }^{23}$ ) or where testing was done anonymously (38\%). ${ }^{24} \mathrm{~A}$ recently published study showed clear gender differences in attitude toward predictive testing, with females having a higher perception than males of their own ability to cope with an adverse result than males and a greater likelihood of disclosing their genetic status to others. ${ }^{20}$

We also found that it was significantly more common for the HD mutation to be carried maternally $(60 \%)$ in the families of those presenting for testing. ${ }^{13,25-27}$ A possible reason that this figure may be skewed is that paternally transmitted HD shows greater average expansion of the CAG repeat number than maternal transmission with a concomitant tendency for earlier onset, thus reducing the opportunity for presymptomatic testing. ${ }^{13,28-32}$

An interesting subset of candidates were those raised away from their biological family, who accounted for $3.2 \%$ of the total cohort. Within this group, $95 \%$ were found to be at risk of inheriting the expanded allele from their mother (compared with $60 \%$ for the total cohort). One possible reason for this extreme skewing is that children are more likely to be raised outside the family when the affected parent is the mother. Kessler states "when the mother is affected it appears to have a greater impact on effective family functioning than when the father is affected." 33 Another possible explanation is that it may be easier for an adoptee to find details of his/her biological mother than his/her biological father on public record.

The distance a candidate lives from the testing center affected the likelihood of completing testing. Although the DNA test continues to be done in Melbourne, efforts are being made to accommodate the needs of distant candidates by co-scheduling multiple consultations to reduce visits to the center and providing alternative means for some of the pre- and post-test counseling. The options include the use of local community health professionals, the HD Association, an increasing number of outreach genetics clinics, and telephone counseling with the metropolitan-based counselor. A similar situation is described by Benjamin and colleagues, ${ }^{34}$ relating to testing in British Columbia, where counseling services within the local community have been developed with appropriate support from the genetics center to help overcome the tyranny of distance.

The timing of testing is a complex issue that seems to be influenced by a number of interrelated factors. These include proximity to the mean perceived age of onset, ${ }^{26,35,36}$ prior exposure to and knowledge of $\mathrm{HD}$, level of risk, and length of time the individual's own risk has been recognized.

In certain respects our findings closely parallel the Canadian experience, where the overall mean age was 39.3 years (compared with our 40.4 years) and $64.7 \%$ already had children (compared with 67\%). ${ }^{14,18}$ However, we observed two peaks in the age distribution curve both for males and females, one in the late 20 s to early 30 s and the other in the late 40 s. This may suggest that there are different age-related motives for testing: one a reproductive risk decision and another to clarify the risk for their children.

The length of time people wait before presenting is strongly influenced by the level of their prior exposure to HD and the age at which they first knew of their risk. These two factors are interrelated, because the risk is learned earlier in families in whom individuals are exposed to advanced HD. Despite knowing of their risk from a relatively early age, individuals in this group wait on average for 13.4 years to present for testing, with many waiting in excess of 20 years (Fig. 3). Although being older when they learn of their risk, the majority of those with little or no exposure to HD sought testing within 1 year. This suggests a more spontaneous and perhaps less considered response to learning of their risk, possibly influenced by a lack of information. Exploration of issues during counseling may lead to a reassessment of the desire to know, with a consequently higher withdrawal rate in this group. Further support for this hypothesis comes from the "adoptee" group. They learned of their risk late (mean age 34.3 years), only one third 
of them reported any direct exposure to HD, and 57\% were tested within 1 year. The level of prior knowledge for those inheriting alleles of reduced penetrance is also often minimal because the disease in such families tends to be of later onset. ${ }^{32,37,38}$ They represent the oldest group, presenting for testing at a mean age of 55.4 years. This study serves to illustrate the significance of the candidates' exposure to HD and the impact it has on the timing and completion of testing.

Of individuals receiving a result, $37.5 \%$ were gene positive, which is in line with most other reports reporting a range from $31.5 \%$ to $45 \% .12-15,17-22$ This is to be expected because $11.3 \%$ of candidates were at less than $50 \%$ risk, and individuals born at $50 \%$ risk and who present for testing as adults have a significantly lesser risk the longer they remain asymptomatic. ${ }^{39,40}$ The fact that a proportion of the at-risk population become symptomatic and thus ineligible for predictive testing is likely to account for the gene-positive group being younger (mean age 37.1 years) than the gene-negative (42.6 years) or "reduced penetrance" candidates (55.4 years).

A number of studies have looked at the reasons why "atrisk" individuals choose not to participate in predictive testing. ${ }^{41-45}$ However, few have considered those who commence testing but withdraw without learning their genetic status, except in relation to the testing of those at $25 \%$ risk. ${ }^{15,45-48}$ Although we cannot specifically address the reasons for withdrawal because of the retrospective nature of the study, we attempted to profile the members of this group. The overall rate of withdrawal in this study is $14.3 \%(108 / 756)$, which is low by international standards; $51 \%$ withdrew in an Italian study, ${ }^{49} 25 \%$ of those at 50\% risk withdrew in the United Kingdom, ${ }^{34}$ and 23\% withdrew in Leiden, The Netherlands. ${ }^{15,48}$

The stage in the process at which withdrawal occurred varied. By definition, all had at least one session of face-to-face counseling. Almost half (45\%) proceeded with blood collection and/or neurologic or neuropsychiatric assessment, together with multiple counseling sessions. In 19\% of cases all clinical consultations were undertaken, but the candidate chose not to receive their result.

The data gave a picture of those most likely to withdraw as being relatively young (especially if female) and childless, lacking significant knowledge of or exposure to severe $\mathrm{HD}$, and having knowledge of their own risk for a relatively short period. Those at $25 \%$ or less risk were overrepresented in this group. It may be that the dynamic process of the program prompted reassessment of their desire to know their genetic status, realizing the severity and inevitability of the disease. Factors that did not seem to be relevant include the gender of either the candidate or the family carrier, and whether or not the candidate was raised away from his or her biological family.

In summary, data from our study are broadly in keeping with international observations with respect to parameters such as age at presentation, "at-risk" status, gender balance, family history, and distribution of genotypes. The major contribution of this study centers on the timing of predictive testing within an individual's life experience. We have identified two interrelated experiential factors that strongly influence the length of time people wait once aware of their own risk status before they present for testing and the subsequent likelihood that testing will be followed through to completion. These factors are their level of prior exposure to HD and the age at which they became aware of their own risk status. Those with little knowledge or exposure to HD are significantly more likely to rush into testing and ultimately less likely to elect to receive their results.

\section{ACKNOWLEDGMENTS}

We thank the Australian Huntington Disease Association, the neuropsychiatrists and neurologists associated with the program, and the staff of the Victorian Clinical Genetics Service's Molecular Genetics Laboratory. M.B.D. is a National Health and Medical Research Council Practitioner Fellow.

\section{References}

1. Hayden M. Huntington's chorea. New York: Springer; 1981.

2. Harper P. Huntington's disease. London: WB Saunders; 1991.

3. Gusella JF, Wexler NS, Conneally PM, Naylor SL, et al. A polymorphic DNA marker genetically linked to Huntington's disease. Nature 1983;306:234-238.

4. World Federation of Neurology: Research Committee. Research Group on Huntington's chorea. Ethical issues policy statement on Huntington's disease molecular genetics predictive test. J Neurol Sci 1989;94:327-332.

5. Nasioulas S, Sheffield L, Mansie S, Forrest S. Modified method for the detection of the CAG repeat expansion in Huntington's disease and application to a predictive testing protocol. Mol Diagn 1997;2:53-59.

6. Mansie S, Sheffield L, Forrest S, Chiu E, et al. Selection for presymptomatic testing for Huntington's disease: who decides? A reply from the Victorian Clin Genet Service, Murdoch Institute, Melbourne, Australia. J Med Genet 1996;33:1051-1052.

7. The Huntington's Disease Collaborative Research Group. A novel gene containing a trinucleotide repeat that is expanded and unstable on Huntington's disease chromosomes. Cell 1993;72:971-983.

8. Tassicker RJ. Psychodynamic theory and counseling in predictive testing for Huntington's disease. J Genet Couns 2005;14:99-107.

9. Lathrop GM, Laloul JM, Julier C, Ott J. Multilocus linkage analysis in humans: detection of linkage and estimation of recombination. Am J Hum Genet 1985;37: $482-498$.

10. Potter NT, Spector EB, Prior TW. Technical standards and guidelines for Huntington disease testing. Genet Med 2004;6:61-65.

11. Australian Bureau of Statistics 3218.0 2003-2004 regional population growth, Australia and New Zealand. Preliminary local government area (LGA) populations (at 30 June 2004). Available at: http://www.abs.gov.au/. Accessed August 17, 2005.

12. Harper PS, Lim C, Craufurd D. Ten years of presymptomatic testing for Huntington's disease: the experience of the UK Huntington's Disease Prediction Consortium. J Med Genet 2000;37:567-571.

13. Goizet C, Lesca G, Durr A. Presymptomatic testing in Huntington's disease and autosomal dominant cerebellar ataxias. Neurology 2002;59:1330-1336.

14. Creighton S, Almqvist EW, MacGregor D, Fernandez B, et al. Predictive, pre-natal and diagnostic genetic testing for Huntington's disease: the experience in Canada from 1987 to 2000. Clin Genet 2003;63:462-475.

15. Maat-Kievit A, Vegter-van der Vlis M, Zoeteweij M, Losekoot M, et al. Paradox of a better test for Huntington's disease. J Neurol Neurosurg Psychiatry 2000;69:579-583.

16. Laccone F, Christian W. A recurrent expansion of a maternal allele with $36 \mathrm{CAG}$ repeats causes Huntington disease in two sisters. Am J Hum Genet 2000;66:11451148.

17. Craufurd D, Tyler A. Predictive testing for Huntington's disease: protocol of the UK Huntington's Prediction Consortium. J Med Genet 1992;29:915-918.

18. Bloch M, Fahy M, Fox S, Hayden MR. Predictive testing for Huntington disease: II. Demographic characteristics, life-style patterns, attitudes, and psychosocial assessments of the first fifty-one test candidates. Am J Med Genet 1989;32:217-224.

19. Holloway S, Mennie M, Crosbie A, Smith B, et al. Predictive testing for Huntington disease: social characteristics and knowledge of applicants, attitudes to the test procedure and decisions made after testing. Clin Genet 1994;46:175-180.

20. Taylor S. Gender differences in attitudes among those at risk for Huntington's disease. Genet Test 2005;9:152-157.

21. Taylor SD. Demand for predictive genetic testing for Huntington's disease in Australia, 1987 to 1993. Med J Aust 1994;161:351, 354-355. 


\section{Trembath et al.}

22. Laccone F, Engel U, Holinski-Feder E, Weigell-Weber M, et al. DNA analysis of Huntington's disease: five years of experience in Germany, Austria, and Switzerland. Neurology 1999;53:801-806.

23. Kromberg JG, Krause A, Spurdle AB, Temlett JA, et al. Utilisation of predictive, prenatal and diagnostic testing for Huntington's disease in Johannesburg. S Afr Med J 1999;89:774-778.

24. Visintainer CL, Matthias-Hagen V, Nance MA. Anonymous predictive testing for Huntington's disease in the United States. Genet Test 2001;5:213-218.

25. Markel DS, Young AB, Penney JB. At-risk persons' attitudes toward presymptomatic and prenatal testing of Huntington's disease in Michigan. Am J Med Genet 1987;26:295-305.

26. Decruyenaere M, Evers-Kiebooms G, Boogaerts A, Cassiman JJ, et al. Psychological functioning before predictive testing for Huntington's disease: the role of the parental disease, risk perception, and subjective proximity of the disease. J Med Genet 1999;36:897-905.

27. McCusker EA, Casse RF, Graham SJ, Williams DB, et al. Prevalence of Huntington disease in New South Wales in 1996. Med J Aust 2000;173:187-190.

28. Snell RG, MacMillan JC, Cheadle JP, Fenton I, et al. Relationship between trinucleotide repeat expansion and phenotypic variation in Huntington's disease. Nat Genet 1993;4:393-397.

29. Andrew SE, Goldberg YP, Kremer B, Telenius H, et al. The relationship between trinucleotide (CAG) repeat length and clinical features of Huntington's disease. Nat Genet 1993;4:398-403.

30. Duyao M, Ambrose C, Myers R, Novelletto A, et al. Trinucleotide repeat length instability and age of onset in Huntington's disease. Nat Genet 1993;4:387-392.

31. Merritt AD, Conneally PM, Rahman NF, Drew AL. Juvenile Huntington's chorea. In: Barbeau A, Brunette JR, editors. Progress in neurogenetics. Amsterdam: Excerpta Medica; 1969:645-650.

32. Langbehn DR, Brinkman RR, Falush D, Paulsen JS, et al. A new model for prediction of the age of onset and penetrance for Huntington's disease based on CAG length. Clin Genet 2004;65:267-277.

33. Kessler S. Forgotten person in the Huntington disease family. Am J Med Genet 1993;48:145-150.

34. Benjamin CM, Adam S, Wiggins S, Theilmann JL, et al. Proceed with care: direct predictive testing for Huntington disease. Am J Hum Genet 1994;55:606-617.

35. Rosenblatt A, Brinkman RR, Liang KY, Almqvist EW, et al. Familial influence on age of onset among siblings with Huntington disease. Am J Med Genet 2001;105:399_ 403.
36. Wexler NS, Lorimer J, Porter J, Gomez F, et al. Venezuelan kindreds reveal that genetic and environmental factors modulate Huntington's disease age of onset. Proc Natl Acad Sci U S A 2004;101:3498-3503.

37. Rubinsztein DC, Leggo J, Coles R, Almqvist E, et al. Phenotypic characterization of individuals with 30-40 CAG repeats in the Huntington disease (HD) gene reveals HD cases with 36 repeats and apparently normal elderly individuals with 36-39 repeats. Am J Hum Genet 1996;59:16-22.

38. Brinkman RR, Mezei MM, Theilmann J, Almqvist E, et al. The likelihood of being affected with Huntington disease by a particular age, for a specific CAG size. Am J Hum Genet 1997;60:1202-1210.

39. Harper PS, Newcombe RG. Age at onset and life table risks in genetic counselling for Huntington's disease. J Med Genet 1992;29:239-242.

40. Bonke B, Tibben A, Lindhout D, Clarke AJ, et al. Genetic risk estimation by healthcare professionals. Med J Aust 2005;182:116-118.

41. Evers-Kiebooms G, Swerts A, Cassiman JJ, Van den Berghe H. The motivation of at-risk individuals and their partners in deciding for or against predictive testing for Huntington's disease. Clin Genet 1989;35:29-40.

42. Quaid KA, Morris M. Reluctance to undergo predictive testing: the case of Hunting ton disease. Am J Med Genet 1993;45:41-45.

43. van der Steenstraten IM, Tibben A, Roos RA, van de Kamp JJ, et al. Predictive testing for Huntington disease: nonparticipants compared with participants in the Dutch program. Am J Hum Genet 1994;55:618-625.

44. Binedell J, Soldan JR, Harper PS. Predictive testing for Huntington's disease: I. Predictors of uptake in South Wales. Clin Genet 1998;54:477-488.

45. Decruyenaere M, Evers-Kiebooms G, Boogaerts A, Cloostermans T, et al. Non participation in predictive testing for Huntington's Disease: individual decisionmaking, personality and avoidant behaviour in the family. Eur J Hum Genet 1997;5: 351-363.

46. Benjamin CM, Lashwood A. United Kingdom experience with presymptomatic testing of individuals at 25\% risk for Huntington's disease. Clin Genet 2000;58:41-49.

47. Lindblad AN. To test or not to test: an ethical conflict with presymptomatic testing of individuals at 25\% risk for Huntington's disorder. Clin Genet 2001;60:442-446.

48. Maat-Kievit A, Vegter-Van Der Vlis M, Zoeteweij M, Losekoot M, et al. Predictive testing of 25 percent at-risk individuals for Huntington disease (1987-1997). Am J Med Genet 1999;88:662-668.

49. Mandich P, Jacopini G, Di Maria E, Sabbadini G, et al. Predictive testing for Huntington's disease: ten years' experience in two Italian centres. Ital J Neurol Sci 1998; 19:68-74. 